УДК 528.871.5

\title{
МЕТОДИКА КАРТОГРАФИРОВАНИЯ НЕФТЕЗАГРЯЗНЕННЫХ ЗЕМЕЛЬ СЕВЕРНОГО РЕГИОНА
}

Баутов Илья Александрович Лоншакова Александра Антоновна

студенты

Научный руководитель: Коркина Елена Александровна

к.г.н., доцент

ФГБОУ ВО «Нижневартовский государственный университет»

Аннотация: Освещена актуальная проблема оцифровки данных при современных технологий на территории Западно-Сибирской равнины. Предложена методика картографирования нефтезагрязненных земель по дешифровочным признакам. Разработан четкий алгоритм действий для обработки векторных и растровых изображений, а также определены основные дешифровочные признаки для нефтезагрязненных разливов.

Ключевые слова: Картографирование нефтезагрязненных земель, данные дистанционного зондирования, автоматизированные геоинформационные системы.

\section{METHODOLOGY FOR MAPPING OIL-POLLUTED LANDS OF THE NORTHERN REGION}

\author{
Bautov Ilya Alexandrovich \\ Lonshakova Alexandra Antonovna \\ Scientific adviser: Korkina Elena Aleksandrovna
}

\begin{abstract}
The actual problem of data digitization using modern technologies on the territory of the West Siberian Plain is highlighted. A method for mapping oilcontaminated land by decoding features is proposed. A clear algorithm for processing vector and raster images has been developed, and the main features of decoding oil spills have been identified.

Key words: Mapping of oil-contaminated lands, remote sensing data, automated geoinformation systems.
\end{abstract}


На данный момент остро обсуждаются автоматизированные системы. В современном мире существует множество баз данных, информационных систем, нуждающихся в автоматизации. До 1934 года картографирование земной поверхности производилось вручную экспертом, соответственно, после съемки в натуре. Далее уже внедрили воздушное фотографирование аэрофотосъемку. Изначально данный способ был предложен компаниями интенсивной разведки. И имел ряд преимуществ по сравнению с предыдущим способом - обработка информации в виде изображений Земной поверхности производилась в меньшие сроки, имела малые затраты, а также сводила к минимум погрешности проделанной работы. Правительство оценило новый способ и уже в 1934 году фотографическому отделу военно-воздушного министерства было поручено осуществить воздушное фотографирование. По аэрофотоснимкам, сделанным в масштабе 1:20000, правительственная топографическая служба изготовила способом аэротриангуляции пограничные карты концессий, что обошлось нефтяным компаниям в стоимости наземного картографирования.

Объектом исследования являются нефтезагрязненные земли, располагающиеся на Западно-Сибирской равнине. Территория приурочена к Среднеобской низменности, имеется небольшой уклон в рельефе, его значения колеблются в пределах $1-1,5^{\circ}$, который направлен в р.Обь. [4] Для данной местности характерна эрозионная активность береговой зоны, которая по данным Коркина С.Е. составляет 2-5 м/год, а среднее годовое количество осадков - 450 мм. [5]

Вследствие труднодоступности и заболоченности многих территорий, находящихся в зоне воздействия предприятий нефтедобычи, наиболее перспективным подходом к оценке влияния нефтеразливов на состояние окружающей природной среды является использование данных дистанционного зондирования Земли и геоинформационных систем. [6] Нами были разработаны методические рекомендации при картографировании нефтезагрязненных земель, применяя современные геоинформационные технологии. Характерные преимущества ГИС (Далее - геоинформационные системы), использованные в данной работе для формирования методики Применение актуальных данных дистанционного зондирования, в режиме реального времени предоставлены автоматизированные цифровые базы данных в виде растрового и векторного изображения земной поверхности Среднеобской низменности, так же для современных ГИС большое 
преимущество заключается в наличии цифровых баз данных, таких как географических, геологических, экологических и других, которые рентабельны при картографировании. Незаменимыми свойствами современных программных обеспечений в области картографии являются мультимедийность и вариация дизайнов. Для разработки методики применялись такие ГИС, как MapInfo, ArcGis, Sas.Planet и онлайн системы Яндекс.Карта.

Ханты-Мансийский автономный округ является главным нефтедобывающим центром страны, по данным 2010 года доля ЗападноСибирского нефтегазоносного бассейна составила 63\%. В данное время на территории округа открыто более 360 месторождений нефти и газа, всего объем нефтедобычи в 2011 г. составил 51,3 \% общероссийского объема добываемой нефти [1]. Известно, что в России около 99\% добываемой нефти, более 50\% производимой продукции нефтепереработки перемещается с помощью магистрального трубопроводного транспорта. Значительная часть сетей трубопроводов в районах нефтегазодобычи имеет срок службы более 30 лет, большинство труб и оборудования подвержено коррозии, вследствие чего зачастую случаются аварии на водоводах и нефтепроводах. В результате аварийных нефтеразливов происходит загрязнение атмосферы парами нефти, почвенно-растительного комплекса нефтепродуктами, сульфатами и хлоридами, содержащимися в пластовых водах и загрязнение рек в результатесмыва нефтепродуктов с прилегающих нефтезагрязненных участков водосборов [1].

Нами были исследованы территории Среднеобской низменности, которая относится к широтному отрезку реки Обь и представляет собой выровненную долину с развитым комплексом надпойменных террас и пойменных уровней. Важнейшими социальными объектами в пределах Нижневартовского района здесь являются различные промышленные центры, такие как Самотлорское, Ватинское месторождения добычи нефти. Для нашего исследования были определены основные территории Самотлорского и Покачевского месторождения. Основой для картографирования нашего объекта является данные дистанционного зондирования. При помощи программного обеспечения Sas.Planetконвертируем растровое изображение (сохраняя проекцию и привязку геодезической сети) Покачевского и Самотлоровского месторождения (таб. 1) 
Таблица 1

Координаты местоположения некоторых нефтезагрязненных

земельных участков

\begin{tabular}{|c|c|c|}
\hline $\begin{array}{c}\text { Место разлива } \\
\text { нефтепродуктов }\end{array}$ & Широта & Долгота \\
\hline Покачевское М/C & N61²6'32,9064" & $\mathrm{E}^{\circ} 06^{\circ} 15,1824^{\prime \prime}$ \\
\hline Покачевское М/C & N61 ${ }^{\circ} 27^{\prime} 05,4519^{\prime \prime}$ & $\mathrm{E}^{\circ} 06^{\circ} 49^{\prime} 41,5311^{\prime \prime}$ \\
\hline Покачевское М/C & N61 ${ }^{\circ} 25^{\prime} 53,8076^{\prime \prime}$ & $\mathrm{E}^{\circ} 6^{\circ} 10^{\prime} 11,5578^{\prime \prime}$ \\
\hline Самотлорское M/C & N61 ${ }^{\circ} 25^{\prime} 04,9205^{\prime \prime}$ & $\mathrm{E}^{\circ} 6^{\circ} 36^{\prime} 40,5970^{\prime \prime}$ \\
\hline Самотлорское М/C & N61²4'27,9130" & E76³4'42,1984" \\
\hline
\end{tabular}

Для картографирования объектов необходимо определиться с тематикой будущей карты, в данном случае, по дешифровочным признакам определили нефтезагрязненные участки. На данных дистанционного зондирования четко определены магистральные трубопроводные сети, за счет линейной формы, соответственно, места разливов находятся вблизи трубопроводов (Рис.1).

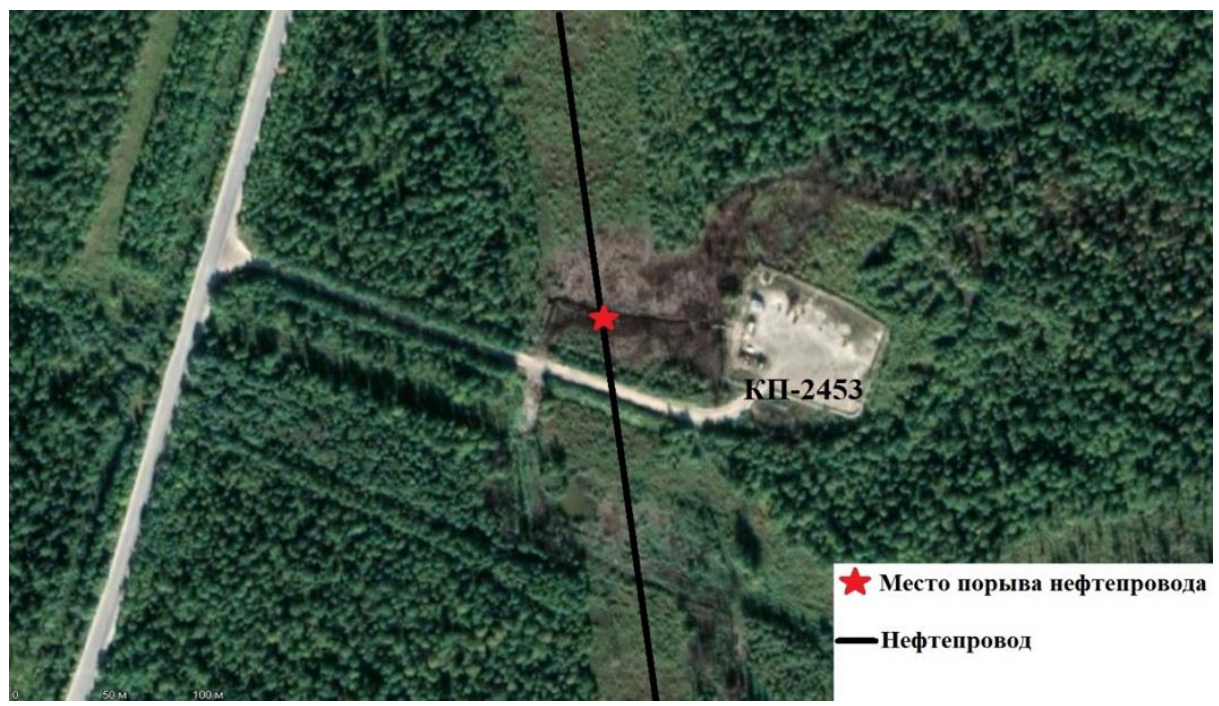

\section{Рис. 1. Генерализация разлива нефти по дешифрированному признаку}

Для выявления нефтезагрязнений на почве используются мультиспектральные космические снимки среднего и высокого пространственного разрешения за летний период с российских и зарубежных спутников Д33. Далее на основе данных признаков используем вид тематического картографирования - способ качественного фона и способ линейных знаков, и точечный способ. Дешифрируемые места разливов нефтепродуктов по цветовым признакам - имеют серовато-коричневый оттенок. Главной особенностью антропогенных объектов, которые 422 
отображаются на снимках, представляется читаемость контуров, форма таких объектов, а также отличимая цветовая гамма. При выявлении их по яркостным признакам появляется сложность в разделении классов объектов, обусловленная близкими значениями величин яркости объектов с аналогичными спектральными признаками. Далее, непосредственно, в MapInfo открываем таблицу, создав новый слой, включив режим редактирования, выделяем полигональными объектами и по такому принципу получаем карту-схему нефтяных разливов на северной части Самотлорского и Покачёвского месторождений (Рис.2).
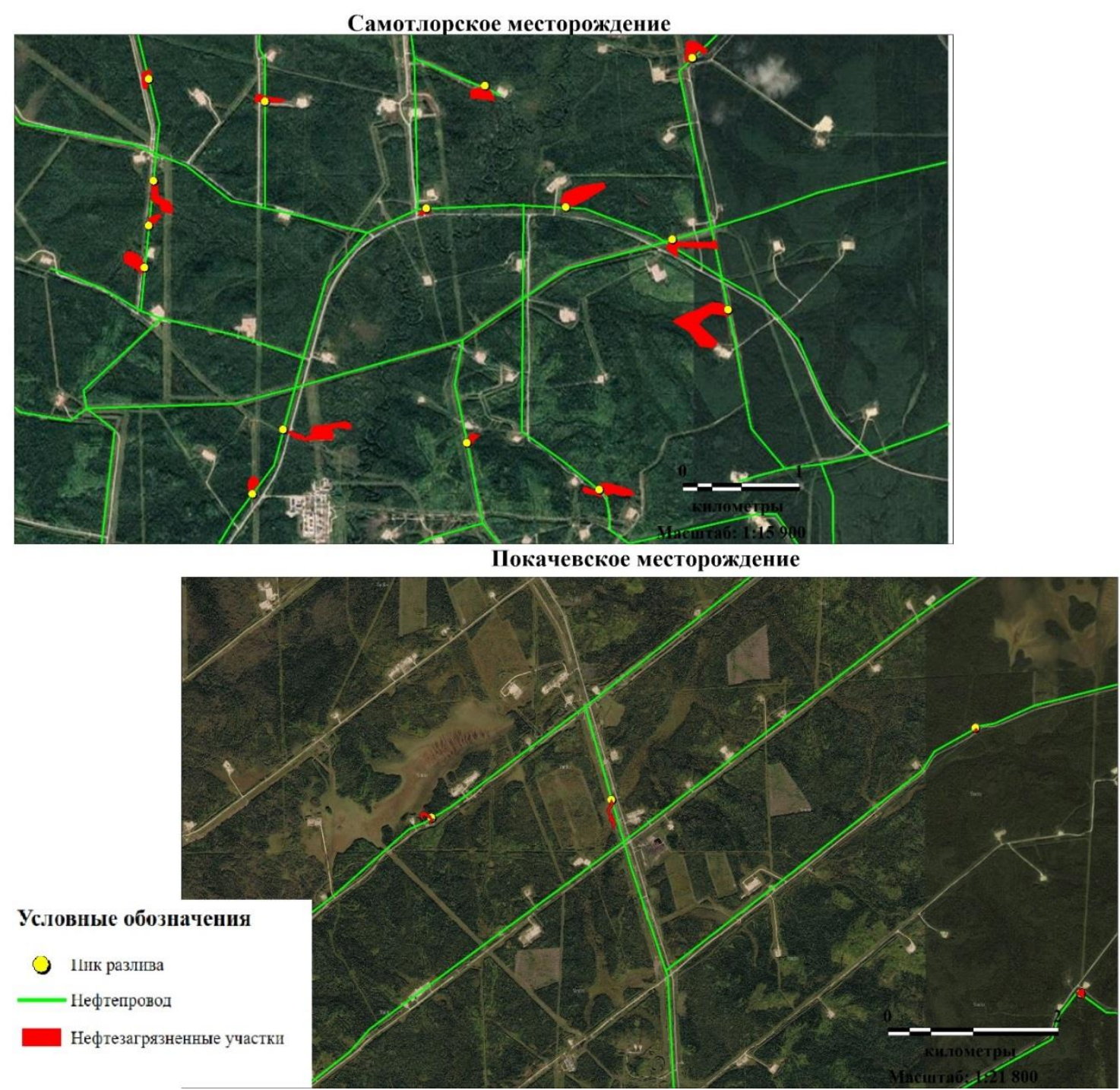

Рис. 2. Карта-схема нефтяных разливов на северной части Самотлорском и Покачёвского месторождении

При помощи программного обеспечения ArcGis разработали схему рекультивационных мероприятий для нефтезагрязненных участков (Рис.3). 
Рекультивация - мероприятия, направленные на восстановление нарушенных земель, в данном случае, загрязненных нефтепродуктами. Проект по восстановлению состоит из основных этапов: биологического и технического этапа.

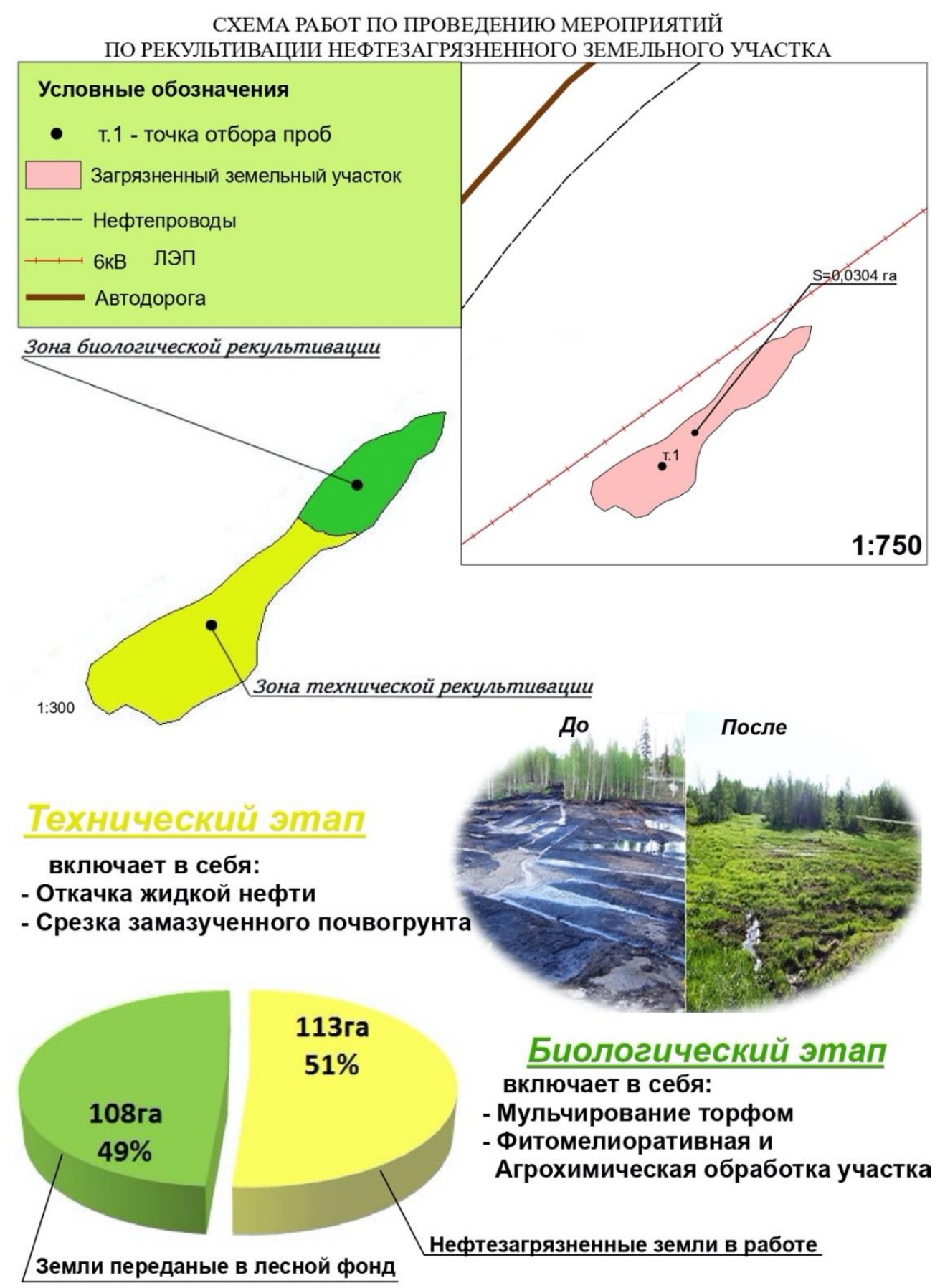

\section{Рис. 3. Схема работ рекультивационных мероприятий для нефтезагрязненных участков}




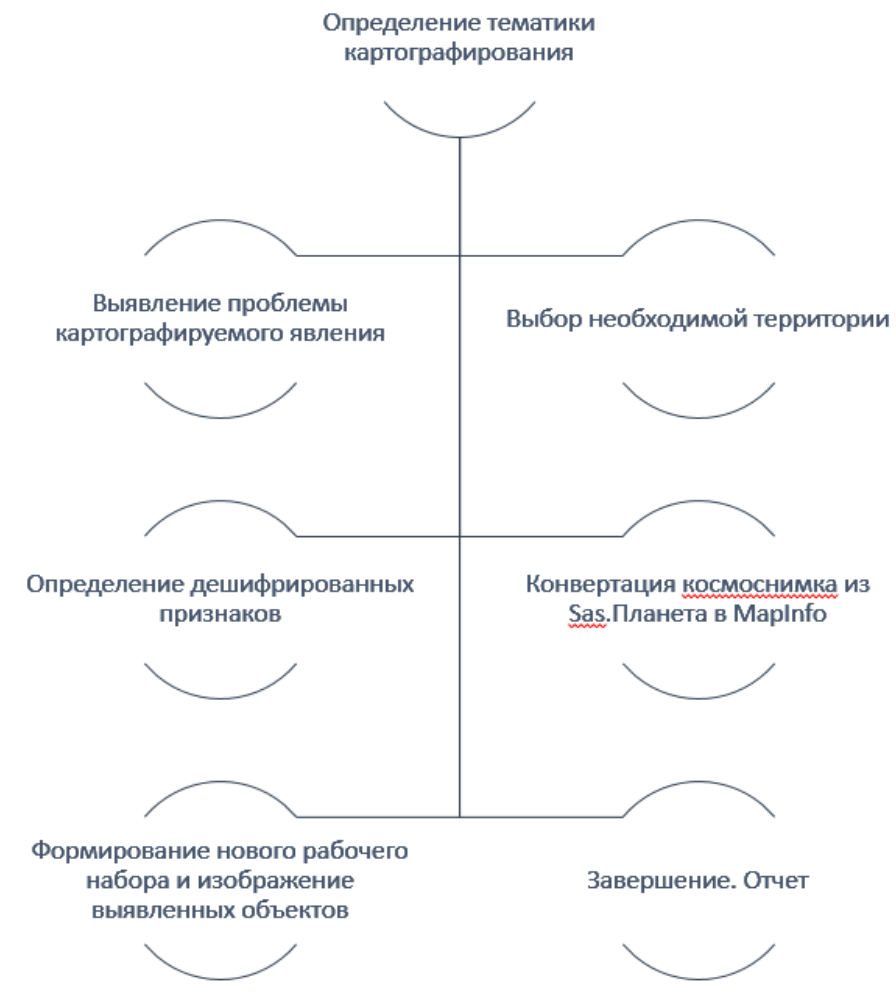

Рис. 4. Методика картографирования при помощи MapInfo

Итак, при помощи современных цифровых программ можно разграничивать территории по определённым классификаторам, в зависимости от тематики картографируемого явления. Исходя из перечисленных действий определим схему последовательности действий при картографировании объектов по дешифрированным признакам (Рис 4). Данные картографирования нефтезагрязненных земель могут применяться для инвентаризации, учёта и определения масштабов катастрофы.

В методическом плане картографирования нефтезагрязненных земель выделяются основные моменты:

геоинформационное обеспечение территории работ;

умение распознавать по дешифровочным признакам;

знаний особенностей орографического пространства;

подготовка эталонов дешифрирования нефтезагрязненных земель на исследуемую территорию;

дешифрирование материалов аэрокосмических съемок с целью выделения границ нефтезагрязненных участков земель. 


\section{Список литературы}

1. Алексеева Мария Николаевна, Ященко Ирина Германовна Использование космических снимков и геоданных для оценки экологических рисков при разливах нефти // Интерэкспо Гео-Сибирь. 2013. №. URL: https://cyberleninka.ru/article/n/ispolzovanie-kosmicheskih-snimkov-i-geodannyhdlya-otsenki-ekologicheskih-riskov-pri-razlivah-nefti (дата обращения: 30.04.2021).

2. Берлянт А.М. Картография: Учебник для вузов. - М.: Аспект Пресс, 2002. - $336 \mathrm{c}$.

3. Колбовский Евгений Юлисович, Брагин Павел Николаевич, Медовикова Ульяна Алексеевна Географические информационные системы для управления ландшафтами на территориях выдающейся природноисторической ценности // Ярославский педагогический вестник. 2012. №4. URL: https://cyberleninka.ru/article/n/geograficheskie-informatsionnye-sistemydlya-upravleniya-landshaftami-na-territoriyah-vydayuscheysya-prirodnoistoricheskoy (дата обращения: 30.04.2021).

4. Коркина Е.А. Самовосстановление нарушенных техногенезом почв Среднего Приобья: монография / Отв. ред. Г.Н. Гребенюк // Г.Н. ГребенюкНижневартовск: Изд-во НВГУ. - 2015.

5. Коркин С.Е., Миронова Н.С., Кайль Е.К. Противоэрозионная организация территории в восточной части широтного отрезка реки Обь на основе мониторинговых данных //Известия Самарского научного центра Российской академии наук. - 2015. - Т. 17. - №. 6-1.

6. Кусков Александр Павлович Применение данных дистанционного зондирования земли при инвентаризации нефтезагрязненных земель // Наука, техника и образование. 2017. №7 (37). URL: https://cyberleninka.ru/article/n/ primenenie-dannyh-distantsionnogo-zondirovaniya-zemli-pri-inventarizatsiineftezagryaznennyh-zemel (дата обращения: 18.05.2021). 